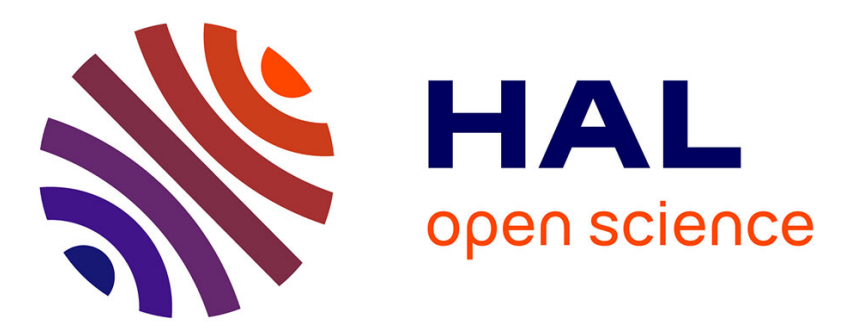

\title{
Low-cost activated carbon for adsorption and heterogeneous ozonation of phenolic wastewater
}

Affoue Tindo Sylvie Konan, Romain Richard, Caroline Andriantsiferana, Kouassi Benjamin Yao, Marie-Hélène Manero

\section{- To cite this version:}

Affoue Tindo Sylvie Konan, Romain Richard, Caroline Andriantsiferana, Kouassi Benjamin Yao, Marie-Hélène Manero. Low-cost activated carbon for adsorption and heterogeneous ozonation of phenolic wastewater. Desalination and Water Treatment, 2019, 163, pp.336-346. 10.5004/dwt.2019.24479 . hal-02309937

\section{HAL Id: hal-02309937 \\ https://hal.science/hal-02309937}

Submitted on 9 Oct 2019

HAL is a multi-disciplinary open access archive for the deposit and dissemination of scientific research documents, whether they are published or not. The documents may come from teaching and research institutions in France or abroad, or from public or private research centers.
L'archive ouverte pluridisciplinaire $\mathbf{H A L}$, est destinée au dépôt et à la diffusion de documents scientifiques de niveau recherche, publiés ou non, émanant des établissements d'enseignement et de recherche français ou étrangers, des laboratoires publics ou privés. 


\section{OATAO}

Open Archive Toulouse Archive Ouverte

\section{Open Archive Toulouse Archive Ouverte}

OATAO is an open access repository that collects the work of Toulouse researchers and makes it freely available over the web where possible

This is an author's version published in: http://oatao.univ-toulouse.fr/24335

Official URL: https://doi.org/10.5004/dwt.2019.24804

\section{To cite this version:}

Konan, Affoué Tindo Sylvie $\leftrightarrows$ and Richard, Romain Caroline $\leftrightarrows$ and Yao, Kouassi Benjamin and Manero, Marie-Hélène 5 Lowcost activated carbon for adsorption and heterogeneous ozonation of phenolic wastewater. (2019) Desalination and Water Treatment, 163. 336346.

Any correspondence concerning this service should be sent to the repository administrator: tech-oatao@listes-diff.inp-toulouse.fr 


\title{
Low-cost activated carbon for adsorption and heterogeneous ozonation of phenolic wastewater
}

\author{
Affoué Tindo Sylvie Konana,b, Romain Richard ${ }^{\mathrm{b}}$, Caroline Andriantsiferana ${ }^{\mathrm{b}, *}$, \\ Kouassi Benjamin Yao, Marie-Hélène Manero ${ }^{\mathrm{b}}$
}

${ }^{a}$ Laboratoire de Procédés Industriels de Synthèse, de l'Environnement et des Energies Nouvelles, Institut National Polytechnique Félix Houphouët-Boigny, BP 1093 Yamoussoukro, Côte d'Ivoire, Tel. +22 508635596; email: affoue.konan@inphb.ci (A.T.S. Konan), Tel. +22 507800519; email: benjamin.yao@inphb.ci (K.B. Yao)

${ }^{b}$ Laboratoire de Génie Chimique, Université de Toulouse, CNRS, INPT, UPS, Toulouse, France, Tel. +33 562258891; email: caroline.andriantsiferana@iut-tlse3.fr (C. Andriantsiferana), Tel. +33 534323626; email: romain.richard@iut-tlse3.fr (R. Richard), Tel. +33 534323704; email: marie-helene.manero@iut-tlse3.fr (M.-H. Manero)

\begin{abstract}
A B S T R A C T
This work is aimed at elaborating an innovative material from palm tree waste that can be used in industrial applications for adsorption and catalytic oxidation. This low-cost activated carbon, elaborated from Borassus palm tree waste (bpAC) showed textural and chemical properties comparable with common activated carbon. Moreover, it demonstrated interesting behaviour when it was coupled with ozone to remove a phenolic compound, 2,4-dimethylphenol (2,4-DMP). This refractory model molecule was removed two times faster in the presence of bpAC and was achieved in only $7 \mathrm{~min}$. The total organic carbon (TOC) removal by only adsorption on bpAC was satisfactory with a value of $93.8 \%$ after $8 \mathrm{~h}$. Nevertheless, the most interesting result concerned the TOC removal during catalytic ozonation which increased from $26 \%$ (single ozonation, i.e., without bpAC) to $91 \%$ in the presence of bpAC. The addition of a radical scavenger (tert-butanol) showed that hydroxyl radicals were involved during ozonation with $\mathrm{bpAC}$. Moreover, a kinetics study highlighted that both radical and molecular mechanisms were acting in heterogeneous reaction. All the results were finally validated by treating real wastewater spiked with 2,4-DMP, confirming the ability of this bpAC to enhance the treatment of phenolic wastewaters.
\end{abstract}

Keywords: Ozonation; Low-cost activated carbon; Adsorption; 2,4-Dimethylphenol; Wastewater treatment

\section{Introduction}

The global market for activated carbon was estimated at around USD 3 billion in 2015, corresponding to a production of nearly 10 million tons, of which about $40 \%$ of the production is used in water treatment plants to produce either high quality drinking water or to treat wastewater. Around the world, particularly in Asia, increasingly restrictive rejection standards involve significant development of wastewater treatment plants and consequently a growing demand of activated carbon. The perspectives are equivalent for the other activated carbon applications: air treatment, purification or storage of gases (30\% of the activated carbon produced), car industry, pharmaceutical/medical and food processing. At medium-term, the demand is expected to dramatically increase since the consumption may triple by 2024 $[1,2]$. Coal, lignite and peat were initially the preferential precursor materials for the production of activated carbons. Nowadays, carbon-rich renewable resources such as stems, shells, husks, seeds or wood are also used. Since activated carbon must be regularly changed due to its loss of efficiency (saturation), low cost materials have been focusing interest 
for several years. Numerous research activities have aimed to find new low-cost precursors, accessible and available in abundant quantities such as rice husk, cashew nut shells, vine shoots, apple pulp and potato waste [2-5]. Many studies have shown comparable efficiency of activated carbon derived from such precursors to commercial adsorbents for wastewater treatment applications: elimination of dyes, metal ions, pharmaceutical products, organic pollutants or natural organic matter [2-3].

Activated carbon is not only used for adsorption applications. Indeed, it can be used as a catalyst support for precious metal or metal oxide to synthesize value-added chemical products (hydrogenation or oxidation for example). Activated carbon may also have catalytic properties for many reactions. Its notable performances are attributed to its large specific surface area, high porosity and excellent electron conductivity [6]. In the field of water treatment, this material is often used to catalyse oxidation reactions. Indeed, Fortuny et al. [7] showed that catalytic effects of activated carbon are comparable with conventional catalysts for degrading phenols using catalytic wet air oxidation $\left(\mathrm{Cu}^{2+}, \mathrm{Fe}^{2+}\right.$, metal oxide, metal supported). This effect has also been demonstrated in photocatalysis where a synergistic effect between activated carbon and $\mathrm{TiO}_{2}$ has been reported by several researchers $[4,8]$.

Oxidation with ozone is one of the most powerful operations for degrading biorefractory compounds but effective purification is sometimes difficult to achieve. Nervertheless, oxidation processes with ozone can be improved by adding an adsorbent in the process. Several studies have dealt with the interest of catalytic ozonation in presence of zeolite or activated carbon (AC) for the last two decades [9-18]. This coupling generates the production of non-selective radicals such as hydroxyl radicals which have a higher oxidation potential than molecular ozone. The heterogeneous catalytic ozonation in the presence of activated carbon was reported to be more efficient than molecular ozonation particularly for the treatment of effluents containing compounds with low biodegradability $[9,14-17,19]$. In all these papers, the reaction kinetics was enhanced due to the decomposition of ozone on the surface of the activated carbon into powerful non-selective free radicals: $\mathrm{HO}^{\bullet}$ and $\mathrm{O}_{2}^{-\bullet}$. All these authors showed that coupling $\mathrm{AC}$ and $\mathrm{O}_{3}$ involves a better efficiency than the addition of the two techniques. The removal process of the contaminant can take place in the bulk phase (homogeneous oxidation) and/or at the AC surface. In so doing, AC may act as an adsorbent and/or as an initiator of free radicals $[20,21]$. The AC physico-chemical properties were found to influence the decomposition of $\mathrm{O}_{3}$ on $\mathrm{AC}$ : Sánchez-Polo et al. [22] and Alvárez et al. [23] evidenced the importance of the specific surface, the mesoporous volume and the presence of basic groups at the surface of the AC. Other researchers [17] suggest that acidic sites can also play a key role in the decomposition of $\mathrm{O}_{3}$ if $\mathrm{pH}>\mathrm{pH}_{\mathrm{PZC}}$.

Many types of wastewaters were efficiently treated by ozonation in presence of $\mathrm{AC}$, with improvements in the mineralization, in the removal of total organic compounds and in the biodegradability of the water: wastewater from the textile industry, water containing humic acids, phtalates, atrazine or dyes $[9,15,24,25]$. So catalytic ozonation on activated carbon appears a very suitable process for water treatment for a variety of industries. Our objective is to show that a low cost and waste-based activated carbon could be used not only as an adsorbent but also as a catalyst for ozone treatments.

In the present work, an innovative low-cost precursor has been used to produce activated carbon, the Borassus (aethiopum specie) palm, available in abundant quantities in tropical regions of Africa and Asia. To produce this activated carbon (bpAC), phosphoric acid has been chosen for chemical activation due to its high efficiency in activation of wood, its low cost and its non-toxicity [26]. For a wastewater treatment application, the 2,4-dimethylphenol (2,4-DMP) was selected as a model molecule as it is representative of toxic biorefractory molecules detected in industrial rejections (disinfectants, solvents, insecticides, pharmaceuticals). After determining the physical and chemical properties of the bpAC, as well as its adsorption properties for 2,4-DMP elimination, this material was used as a catalyst in a lab-scale ozonation process to degrade 2,4-DMP. Experiments were conducted on two aqueous solutions, a synthetic one and a real wastewater spiked with the phenolic pollutant in order to demonstrate the feasibility of this new AC for adsorption and, above all, for catalytic ozonation.

\section{Materials and methods}

\subsection{Reagents}

Analytical grade 2,4-dimethylphenol $\mathrm{C}_{8} \mathrm{H}_{10} \mathrm{O}$ (2,4-DMP, $98 \%$ purity) and tert-butanol $\mathrm{C}_{4} \mathrm{H}_{10} \mathrm{O}(t$-BuOH) were purchased from Sigma-Aldrich (Saint-Louis, Missouri, USA). 2,4-DMP properties are as follows: a molar mass of 122.17 $\mathrm{g} \mathrm{mol}^{-1}$, a boiling temperature of $212^{\circ} \mathrm{C}$, a $\mathrm{pK}_{\mathrm{a}}$ of 10.6 and a kinetic diameter of $7.3 \AA$. Solutions were prepared with water purified by a Millipore Milli-Q UV. Ethanol (EtOH) and methanol $(\mathrm{MeOH})$ used for high-performance liquid chromatography (HPLC) analyses are HPLC grade and were also purchased from Sigma-Aldrich (Saint-Louis, Missouri, USA). Phosphoric acid $\left(\mathrm{H}_{3} \mathrm{PO}_{4}\right)$ was purchased from Merck (Darmstadt, Germany) and the other reagents $\left(\mathrm{HCl}, \mathrm{NaOH}, \mathrm{NaHCO}_{3}, \mathrm{Na}_{2} \mathrm{CO}_{3}\right)$ used in this study were supplied by Sigma-Aldrich (Saint-Louis, Missouri, USA). Dioxygen (>99.99\% purity) was supplied by Linde (SaintPriest, France).

\subsection{Preparation of 2,4 DMP synthetic solutions and spiked samples}

This study was carried out on two aqueous solutions:

- A synthetic solution of 2,4-DMP $\left(50 \pm 2 \mathrm{mg} \mathrm{L}^{-1}\right)$ prepared with water purified by a Millipore Milli-Q UV unit. It was used to study the ozonation of $2,4-\mathrm{DMP}$ in a simple medium without interaction with other organic substances. The concentration of $50 \mathrm{mg} \mathrm{L}^{-1}$ selected in this study is in the concentration range of phenolic compounds in industrial wastes (50 to 2,000 $\mathrm{mg} \mathrm{L}^{-1}$ ) reported by many researchers [27,28]. Moreover, at this concentration, the adsorption does not mask the effects of catalytic ozonation and offers better monitoring of elimination kinetics.

- A wastewater spiked with 2,4-DMP $\left(50 \pm 2 \mathrm{mg} \mathrm{L}^{-1}\right)$ was prepared using $1 \mathrm{~L}$ of filtered (with a sieve of $0.25 \mathrm{~mm}$ 
mesh) effluent sampled from the domestic sewage treatment plant of Nailloux village (Occitanie, France) in which $50 \mathrm{mg}$ of 2,4-DMP was added. It was used to simulate a real medium and to study the performance of the ozonation of 2,4-DMP in complex conditions such as in industrial wastewaters. Its characteristics are detailed in Table 1.

\subsection{Analytical methods}

\subsubsection{Liquid phase analysis}

The 2,4-DMP concentration was determined by HPLC equipped with a UV detector $(280 \mathrm{~nm})$ and a C18 grafted silica column (Zorbax Eclipse XDB-C18, $5 \mu \mathrm{m}$ average, $150 \mathrm{~mm}$ length, $4.6 \mathrm{~mm}$ diameter). Isocratic elution with a solvent mixture of $60 \% \mathrm{EtOH}$ and $40 \%$ ultrapure water was applied at a flow rate of $0.7 \mathrm{~mL} \mathrm{~min}^{-1}$. The liquid samples were filtered through a $0.45 \mu \mathrm{m}$ membrane before being analysed using HPLC.

Degradation of 2,4-DMP leads to many by-products. All the substances contained in the water (intermediates and others) are globally followed by TOC analysis, using a TOC-LCPN Shimadzu (Noisiel, France) apparatus equipped with an infrared detector. The injection volume was $50 \mu \mathrm{L}$. combustion reactions were carried out in a quartz pipe at $680^{\circ} \mathrm{C}$ with a platinum catalyst. Oxygen was used as a carrier gas at a flow rate of $150 \mathrm{~mL} \mathrm{~min}^{-1}$.

\subsubsection{Solid-phase analysis}

Concerning the bpAC, its textural characterization was obtained from nitrogen adsorption at $-193^{\circ} \mathrm{C}$ using an ASAP 2010M apparatus (Micromeritics, Norcross, GA). The specific surface area was determined with the Brunauer, Emmett and Teller method (BET method) for a relative pressure range $\left(p=p_{0}\right)$ of $0.01-0.2$ [29]. Methods from Horvath and Kawazoe [30] and Barrett et al. [31] have been used to assess the micropore and mesopore volumes.

Moreover, the identification and the quantification of the surface functions of bpAC were performed using Boehm titration [32]. For the determination of acid groups, $1 \mathrm{~g}$ of activated carbon was stirred during $72 \mathrm{~h}$ with $50 \mathrm{~mL}$

Table 1

Characteristics of the effluent sampled from the domestic sewage treatment plant of Nailloux

\begin{tabular}{ll}
\hline $\mathrm{pH}$ & 8 \\
$\mathrm{BOD}\left(\mathrm{mg}_{\mathrm{O} 2} \mathrm{~L}^{-1}\right)$ & 2 \\
$\mathrm{COD}\left(\mathrm{mg}_{\mathrm{O} 2} \mathrm{~L}^{-1}\right)$ & 30 \\
$\mathrm{TOC}\left(\mathrm{mg}_{\mathrm{C}} \mathrm{L}^{-1}\right)$ & 4 \\
Ammonium $\left(\mathrm{mg}_{\mathrm{N}} \mathrm{L}^{-1}\right)$ & 0.9 \\
Nitrogen Kjeldahl $\left(\mathrm{mg}_{\mathrm{N}} \mathrm{L}^{-1}\right)$ & 2.1 \\
Nitrates $\left(\mathrm{mg} \mathrm{L}^{-1}\right)$ & 1.5 \\
Nitrites $\left(\mathrm{mg} \mathrm{L}^{-1}\right)$ & 0.5 \\
Total phosphorus $\left(\mathrm{mg} \mathrm{L}^{-1}\right)$ & 0.3 \\
IC $\left(\mathrm{mg} \mathrm{L}^{-1}\right)$ & 79 \\
\hline
\end{tabular}

BOD: biochemical oxygen demand; COD: Chemical oxygen demand. of a solution $\left(\mathrm{NaHCO}_{3}, \mathrm{Na}_{2} \mathrm{CO}_{3}\right.$ or $\left.\mathrm{NaOH}\right)$ at $0.1 \mathrm{~mol} \mathrm{~L}-1$. To determine the basic groups, the same operations were led with a solution of $\mathrm{HCl}$ at $0.1 \mathrm{~mol} \mathrm{~L}{ }^{-1}$. The basic or acid reactional volume was determined by titration with a solution of $0.1 \mathrm{~mol} \mathrm{~L}^{-1}$ of $\mathrm{HCl}$ or $\mathrm{NaOH}$, respectively, for the acid and basic surface functions.

Finally, the $\mathrm{pH}$ of the point of zero charge $\left(\mathrm{pH}_{\mathrm{PzC}}\right)$ was determined according to the so-called drift method [33], which consists in treating, during $48 \mathrm{~h}, 50 \mathrm{~mL}$ of $\mathrm{NaCl}$ solutions $\left(0.01 \mathrm{~mol} \mathrm{~L}^{-1}\right)$ with $0.15 \mathrm{~g}$ of bpAC at different $\mathrm{pHs}$. The $\mathrm{pH}_{\mathrm{PZC}}$ is obtained when $\mathrm{pH}_{\text {final }}$ is equal to $\mathrm{pH}_{\text {initial }}$.

\subsection{Production and characterization of activated carbon}

The innovative activated carbon (bpAC) was prepared using Borassus palm collected in the locality of Yamoussoukro (Côte d'Ivoire). The petioles of these palms were cut-up, washed and sun-dried during three days (Fig. 1a).

The dried samples were impregnated in a solution of orthophosphoric acid $\left(\mathrm{H}_{3} \mathrm{PO}_{4}\right)$ at $3 \mathrm{~mol} \mathrm{~L}^{-1}$ for $24 \mathrm{~h}$ and then carbonized at $600^{\circ} \mathrm{C}$ for $3 \mathrm{~h}$ under non-controlled atmosphere. The residues of carbonization were eliminated by an abundant washing with distilled water. In order to know if the activated carbon produced contained phosphorus, the orthophosphate content was regularly checked during washing. The final content was $0.01 \mathrm{mg} \mathrm{L}^{-1}$. Then, activated carbon was dried at $105^{\circ} \mathrm{C}$ for $24 \mathrm{~h}$ and crushed in order to obtain a material with a granulometry of less than $500 \mu \mathrm{m}$. The final granular bpAC can be seen in Fig. 1b.

\subsection{Experimental setup}

The experiments were carried out in a semi-batch stirred slurry glass reactor (height: 0.26 m; diameter: 0.10 m; Fig. 2) with a jacket allowing to maintain a constant temperature $\left(25^{\circ} \mathrm{C}\right)$. A volume of $1 \mathrm{~L}$ of the aqueous solution of 2,4 -DMP was introduced into the reactor containing $5 \mathrm{~g}$ of bpAC. The reactor was provided with a syringe dipping into the reactor for liquid sampling. Ozone $\left(\mathrm{O}_{3}\right)$ was produced by an ozone generator (WEDECO type modular $4 \mathrm{HC}$ ) fed with pure dioxygen. Ozonated stream was continuously added to the reactor at a flow rate of $30 \mathrm{~L} \mathrm{~h}^{-1}$ and a $10 \mathrm{~g} \mathrm{~m}^{-3}$ (NTP) ozone concentration. Thanks to this flow rate, a maximum amount of ozone in the liquid phase is obtained, which guarantees that ozone is not the limiting reagent. As a result, the kinetics being independent of ozone concentration, it can be considered of pseudo-first order. It was introduced through a tube provided with a porous diffuser placed under the turbine, to ensure a satisfactory mixing of liquid and gaseous phases. UV ozone analyser (BMT 964) was used to measure ozone gas concentrations at the inlet and outlet of the reactor. It was connected to a computer for continuous data acquisition. The off-gas was driven to an ozone thermal destructor before being released to the atmosphere.

To study the adsorption kinetics, $5 \mathrm{~g}$ of bpAC were introduced into the same reactor without any gas supply. The adsorption isotherm experiments were performed at $25^{\circ} \mathrm{C}$ in $125 \mathrm{~mL}$ stirred flasks, $0.1 \mathrm{~g}$ of bpAC with $100 \mathrm{~mL}$ of 2,4-DMP at different concentrations (in the range $0-1 \mathrm{~g} \mathrm{~L}^{-1}$ ). 

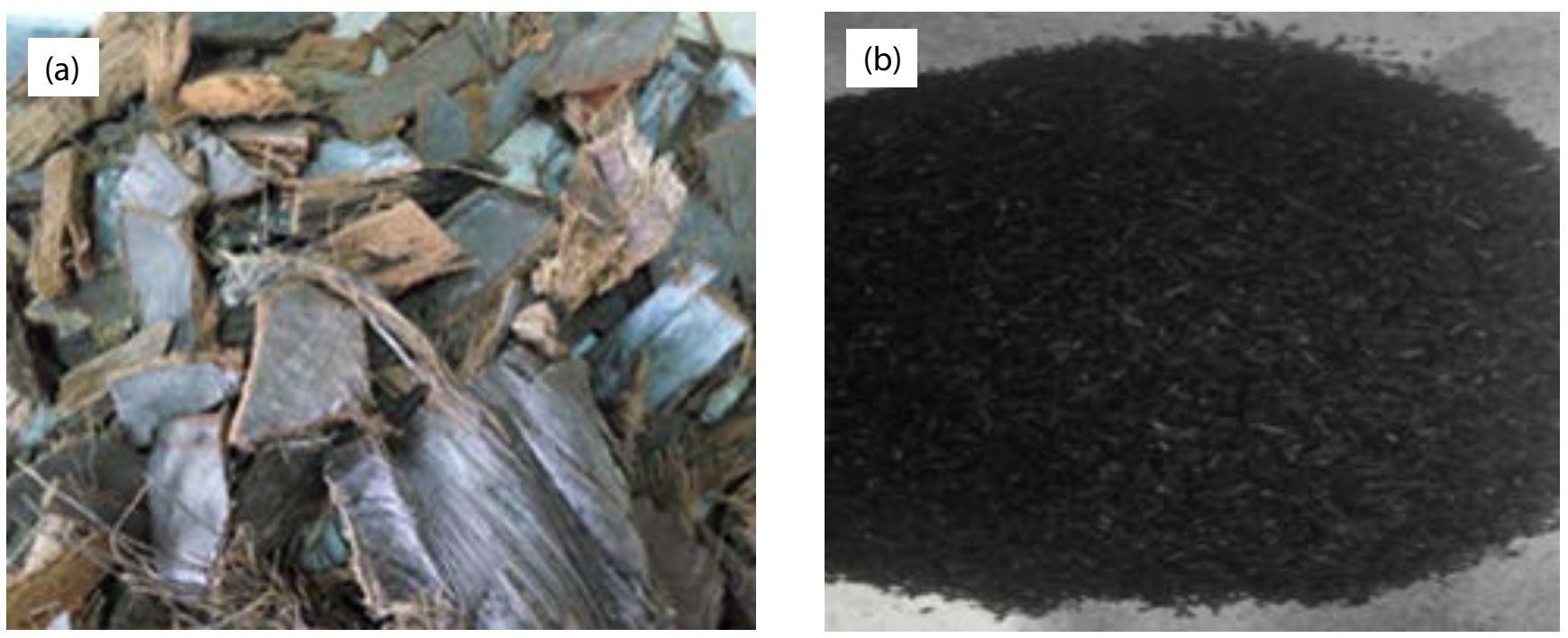

Fig. 1. Raw Borassus palm (a) and activated carbon produced (b).

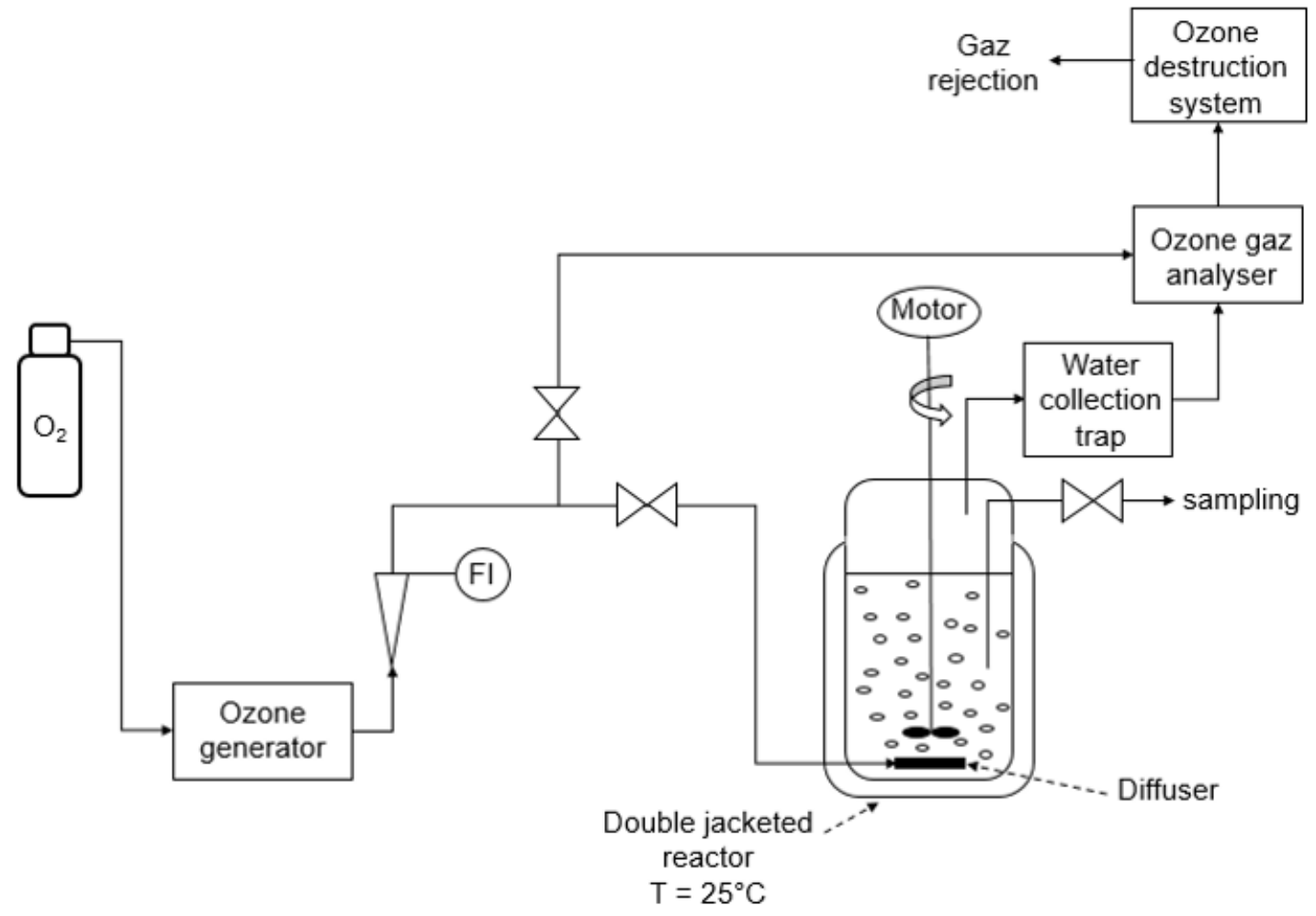

Fig. 2. Schematic diagram of experimental setup.

\subsection{Kinetic model}

Organic compounds removal by the $\mathrm{O}_{3} / \mathrm{bpAC}$ coupling results from a complex combination of homogeneous (liquid phase) and heterogeneous reactions (on the surface of bpAC). Therefore, to better understand the mechanisms involved and in order to compare ozonation processes and adsorption under the same conditions, the kinetic study was performed on the first $5 \mathrm{~min}$. As in the other

studies in the literature $[17,21,22,24]$, it was figured that the catalytic ozonation could be the result of five mechanisms. Each one was identified with its kinetics law and the simplified global kinetic law can be obtained by summing all the kinetic laws. For ozonation reactions (directly with $\mathrm{O}_{3}$ or indirectly with $\mathrm{HO}^{\circ}$ ), it is generally admitted that the kinetics is correctly described by a reaction of global order $2[25,34]$. Several hypotheses have been made to determine the kinetics law governing the phenomena in coupling 
$\mathrm{O}_{3} /$ bpAC: (i) dissolved $\mathrm{O}_{3}$ concentration in solution is assumed to be constant over time (as explained in the previous paragraph); (ii) hydroxyl radical ( $\mathrm{HO}^{*}$ ) concentration can also be assumed to be constant. In order to simplify the global model, it was assumed that the adsorption kinetics could be depicted by a pseudo-first order model $[24,35]$.

In homogeneous phase ([2,4-DMP] represents the concentration of 2,4-DMP in the bulk phase):

- Direct ozonation due to a molecular type reaction between $\mathrm{O}_{3}$ and the pollutant.

$-\frac{d[2,4-\mathrm{DMP}]}{d t}=k_{1}[2,4-\mathrm{DMP}]\left[\mathrm{O}_{3}\right]=k_{1 \mathrm{obs}}[2,4-\mathrm{DMP}]$

- Indirect ozonation, due to a radical-type reaction (the radicals resulting from the decomposition of $\mathrm{O}_{3}$ in water).

$$
-\frac{d[2,4-\mathrm{DMP}]}{d t}=k_{2}[2,4-\mathrm{DMP}]\left[\mathrm{HO}^{\bullet}\right]=k_{2 \mathrm{obs}}[2,4-\mathrm{DMP}]
$$

In heterogeneous phase ([2,4-DMP] represents the concentration of adsorbed 2,4-DMP in equilibrium with the 2,4-DMP in the bulk phase through the Freundlich type equilibrium isotherm):

- Adsorption of pollutant on the bpAC.

$$
-\frac{d[2,4-\mathrm{DMP}]}{d t}=k_{3}[2,4-\mathrm{DMP}]
$$

- Direct ozonation of adsorbed products on the bpAC (molecular oxidation).

$$
-\frac{d[2,4-\mathrm{DMP}]}{d t}=k_{4}[2,4-\mathrm{DMP}]\left[\mathrm{O}_{3}\right]=k_{4 \mathrm{obs}}[2,4-\mathrm{DMP}]
$$

- Indirect ozonation of products adsorbed on the bpAC (radical oxidation).

$$
-\frac{d[2,4-\mathrm{DMP}]}{d t}=k_{5}[2,4-\mathrm{DMP}]\left[\mathrm{HO}^{\bullet}\right]=k_{5 \mathrm{obs}}[2,4-\mathrm{DMP}]
$$

Thus, the elimination kinetics of 2,4-DMP by single ozonation can be modelled by:

$$
\begin{aligned}
& -\frac{d[2,4-\mathrm{DMP}]}{d t}=k_{1 \mathrm{obs}}[2,4-\mathrm{DMP}]+k_{2 \mathrm{obs}}[2,4-\mathrm{DMP}] \\
& -\frac{d[2,4-\mathrm{DMP}]}{d t}=k_{\text {homo }}[2,4-\mathrm{DMP}]
\end{aligned}
$$

With:

$$
k_{\text {homo }}=k_{\text {1obs }}+k_{\text {2obs }}
$$

$k_{\text {homo }}$ represents the kinetic constant of reactions (direct or indirect) occurring in liquid phase in absence of bpAC $\left(\mathrm{min}^{-1}\right) . k_{\text {homo }}$ can be deducted with the slope of the curve $\ln [2,4-\mathrm{DMP}]=f(t)$ for single ozonation.
The elimination kinetics of 2,4-DMP by catalytic ozonation has been simplified as follows:

$$
-\frac{d[2,4-\mathrm{DMP}]}{d t}=k_{\text {global }}[2,4-\mathrm{DMP}]
$$

With:

$$
k_{\text {global }}=k_{\text {homo }}+k_{\text {hetero }}
$$

$k_{\text {hetero }}=k_{3}+k_{4 \mathrm{obs}}+k_{5 \mathrm{obs}}$

$k_{\text {hetero }}$ represents the mechanisms occurring on bpAC surface involving the elimination of 2,4-DMP at the bpAC surface by adsorption, degradation by molecular ozone and also by radical mechanisms. Likewise, the representation of $\ln [2,4-\mathrm{DMP}]=f(t)$ enables the determination of $k_{\text {global }}$ and the deduction of the value of $k_{\text {hetero }}$.

The contribution of heterogeneous mechanisms $\left(\delta_{\text {hetero }}\right)$ in the $\mathrm{O}_{3} / \mathrm{bpAC}$ coupling is given by Eq. (12):

$\delta_{\text {hetero }}=\frac{k_{\text {hetero }}}{k_{\text {global }}} \times 100=\frac{\left(k_{\text {global }}-k_{\text {homo }}\right)}{k_{\text {global }}} \times 100$

Eqs. (13) and (14) allow to model 2,4-DMP removal kinetics for experiments performed on the synthetic water with $\mathrm{O}_{3}$, bpAC and the radical scavenger $t$-BuOH [24]:

$$
\begin{aligned}
& \frac{d[2,4-\mathrm{DMP}]}{d t}=k_{1 \mathrm{obs}}[2,4-\mathrm{DMP}]+k_{3}[2,4-\mathrm{DMP}]+ \\
& k_{4 \mathrm{obs}}[2,4-\mathrm{DMP}] \\
& -\frac{d[2,4-\mathrm{DMP}]}{d t}=k_{\mathrm{mol}}[2,4-\mathrm{DMP}]
\end{aligned}
$$

$k_{\text {mol }}$ represents the kinetic constant of reactions due to molecular ozone and also adsorption onto the bpAC.

The estimation of the kinetic contribution of radical reactions ( $\delta^{\mathrm{HO}}$ to $2,4-\mathrm{DMP}$ removal is given by Eq. (15):

$\delta^{\mathrm{HO} \cdot}=\frac{k_{\text {global }}-k_{\text {mol }}}{k_{\text {global }}} \times 100$

\section{Results and discussion}

\subsection{Properties of the bpAC and adsorption capacities}

The prepared bpAC from Borassus palm was characterized in terms of textural properties, chemical attributes and adsorption capacities thanks to the techniques previously described. These properties are compared with those of commercial activated carbons prepared from natural raw materials (Table 2).

The BET surface area is quite high $\left(888 \mathrm{~m}^{2} \mathrm{~g}^{-1}\right)$, giving to this adsorbent an interesting retention capacity. Indeed, the value is consistent with usual commercial activated carbon BET values, from 980 to $1,860 \mathrm{~m}^{2} \mathrm{~g}^{-1}$ for ACs selected. Equivalent values were found for mesoporous $\left(0.32 \mathrm{~cm}^{3} \mathrm{~g}^{-1}\right)$ 
Table 2

Characterization of bpAC and commercial activated carbons [36-38]

\begin{tabular}{|c|c|c|c|c|c|}
\hline $\begin{array}{l}\text { Activated } \\
\text { carbons }\end{array}$ & $\begin{array}{l}S_{\mathrm{BET}} \\
\left(\mathrm{m}^{2} \mathrm{~g}^{-1}\right)\end{array}$ & $\begin{array}{l}V_{\text {porous }}\left(\mathrm{cm}^{3} \mathrm{~g}^{-1}\right) \\
\mathrm{mi} / \mathrm{me}\end{array}$ & $\begin{array}{l}\text { Acidic group } \\
\mathrm{Car} / \mathrm{Lac} / \mathrm{Ph}\left(\mathrm{meq} \mathrm{g}^{-1}\right)\end{array}$ & $\begin{array}{l}\text { Total acidic/basic } \\
\text { groups (meq g-1) }\end{array}$ & $\mathrm{pH}_{\mathrm{PZC}}$ \\
\hline bpAC & 888 & $0.35 / 0.32$ & $1.02 / 1.07 / 0.66$ & $2.75 / 0$ & 2.4 \\
\hline PICA S23 & 1,230 & $0.49 / 0.04$ & $0.00 / 0.09 / 0.21$ & $0.30 / 0.98$ & 9.7 \\
\hline PICA L27 & 1,860 & $0.77 / 0.48$ & $\mathrm{NC}$ & $1.85 / 0.59$ & 6.2 \\
\hline MERCK 2514 & 980 & $0.37 / 0.20$ & $0.035 / 0.015 / 0.16$ & $0.22 / 0.46$ & 8.9 \\
\hline 1240 Ceca & 980 & $0.39^{a}$ & $0.00 / 0.06 / 0.00$ & $0.06 / 0.54$ & 9.3 \\
\hline
\end{tabular}

mi: microporous, me: mesoporous; Car: carboxylic, Lac: lactonic, Ph: phenolic; NC: not communicated.

${ }^{a}$ Total porous volume.

and microporous $\left(0.35 \mathrm{~cm}^{3} \mathrm{~g}^{-1}\right)$ volumes, as expected for AC prepared from agricultural residues $[39,40]$. Because of the activating treatment used, many acidic functions were generated at the surface of bpAC. That's why carboxylic and lactonic groups are predominant at its surface. The low $\mathrm{pH}_{\mathrm{PZC}}$ value of our activated carbon (2.4) is due to the activating chemical agent we used: $\mathrm{H}_{3} \mathrm{PO}_{4}$. Because of its high phosphorus and oxygen content, the $\mathrm{H}_{3} \mathrm{PO}_{4}$ chemical activation process generates acidic ACs. The other ACs in Table 2 are commercial and have been activated by a physical process which leads to higher $\mathrm{pH}_{\mathrm{PZC}}$. In the literature, researchers found $\mathrm{pH}_{\mathrm{PZC}}$ values (of activated carbons prepared by chemical activation with $\mathrm{H}_{3} \mathrm{PO}_{4}$ ) ranging from 2.4 to 1.9, depending on the level of impregnation [41-43], which is comparable with ours. Other researchers have obtained slightly higher $\mathrm{pH}_{\mathrm{pzC}}$ values of 3.2 [44] or 3.5 [45].

Concerning adsorption properties, isotherm experiments were carried out with 2,4-DMP in contact with bpAC at $25^{\circ} \mathrm{C}$. Compared with commercial adsorbents, bpAC showed good retention capacities of 2,4-DMP totally consistent with other activated carbon results (Table 3). Equilibrium adsorption capacities of bpAC are lower than commercial ACs (ratio between 0.25 and 0.5 ) but they are significantly higher than the values obtained for different adsorbents such as ZSM-R and Mordenite and rather the same than Faujasite- $\gamma$.

Even if its smallest specific surface area impacts its adsorption capacity, the lower adsorption performance of bpAC compared with commercial AC is mostly due to the presence of many acidic functions on its surface. These functions are generally unfavourable for the adsorption of phenolic compounds. They are used to retain water molecules by $\mathrm{H}$-bonds and therefore compete with the targeted molecules. This phenomenon is also accentuated by the absence of basic groups. Indeed, as widely accepted, the adsorption mechanism is based on $\pi-\pi$ dispersion interactions between the $\pi$-electrons of aromatic ring and the $\pi$-electrons of the activated carbon: the presence of basic functional groups has been considered to favour these interactions ( $\pi$-electron rich functional groups). The absence of basic oxygen functions at the surface of the bpAC therefore tends to be a disadvantage for these interactions [48]. Finally, the Freundlich model, typical of multilayer adsorptions, correctly represents the adsorption isotherm at $25^{\circ} \mathrm{C}$, which can be explained by the micro-mesoporous properties of bpAC. Concerning Freundlich constants, the high value of $n$ $(0.1<1 / n<1)$ indicates the stronger adsorption interactions between adsorbate and adsorbent [49]; the low value of $K_{F}$ is in agreement with the weakest adsorption capacities of bpAC.

\subsection{Oxidation of 2,4-DMP: single and catalytic ozonation}

As expected, 2,4-DMP can be easily removed by single ozonation, without any catalyst (Fig. 3a). Indeed, 2,4-DMP has a high electron density thanks to its aromatic structure and its double bonds, and the electron-donating group $-\mathrm{OH}$. Ozone, which is an electrophilic agent, strongly reacts with this type of molecule: its electrophilic attack opens the aromatic rings, leading to the formation of carboxylic acid compounds. Other works found the same fast 2,4 DMP removal by single ozonation, even with other concentrations $[10,48,50-52]$. Thanks to the addition of bpAC, the kinetics of reaction is highly increased, from 0.31 to $0.69 \mathrm{~min}^{-1}$ (Table 4). It is difficult to draw comparison with the results of other researchers due to different experimental conditions, however, activated carbon always increases the reaction rate of the contaminant if the $\mathrm{pH}$ is not too acidic and if the water does not contain radical scavengers [20]. Moreover, the contribution of activated carbon is interesting when considering the by-products of the oxidation reaction. Indeed, it can be seen in Fig. $3 b$ that only $26.0 \%$ of the TOC is removed during single ozonation whereas $91.4 \%$ of the TOC is eliminated during catalytic ozonation (in the presence of $5 \mathrm{~g} \mathrm{~L}^{-1}$ of bpAC). Other works found almost the same increase (300\%) with $2 \mathrm{~g} \mathrm{~L}^{-1}$ of $\mathrm{Al}_{2} \mathrm{O}_{3}$ and with an $\mathrm{O}_{3}$ dose of $2 \mathrm{~g} \mathrm{~m}^{-3}$ [52]. In addition, an acidification of the medium is also noted, the $\mathrm{pH}$ decreasing from 5.3 to 3.1 and from 5.3 to 1.7 for single ozonation and catalytic ozonation, respectively, confirming the generation of acidic species. With bpAC, this $\mathrm{pH}$ decrease could be (i) due to the degradation of bpAC surface by ozone attack $[14,53]$ and also (ii) due to the consequence of the leaching of residual phosphoric acid contained inside the pores even though it has been carefully rinsed.

Interesting results in terms of TOC adsorption (Fig. 3b) were obtained with $93.8 \%$ of TOC elimination after $8 \mathrm{~h}$. Nevertheless, in this adsorption experiment, there is no oxidation and only the 2,4-DMP molecule was considered among the TOC. In the context of this study, the objective was not only to adsorb the 2,4-DMP molecule but also to completely degrade it (and reach a total mineralisation).

The presence of the bpAC, therefore, has a very significant impact on the overall yield of the reaction and proceeds 
Table 3

Adsorption capacities for various 2,4-DMP/adsorbent systems [10,46,47]

\begin{tabular}{|c|c|c|c|c|}
\hline Adsorbent (reference) & $S_{\mathrm{BET}}\left(\mathrm{m}^{2} \mathrm{~g}^{-1}\right)$ & Operating conditions & $q_{e}\left(\mathrm{mg} \mathrm{g}^{-1}\right)$ & Appropriated model $\left(R^{2} ; 1 / n ; K\right)$ \\
\hline bpAC (our work) & 888 & $\begin{array}{l}C_{\text {adsorbent }}=1 \mathrm{~g} \mathrm{~L}^{-1} ; T=25^{\circ} \mathrm{C} \\
0<C_{0}<1,000 \mathrm{mg} \mathrm{L}^{-1}\end{array}$ & $\begin{array}{l}47^{a} \\
130^{b}\end{array}$ & $\begin{array}{l}\text { Freundlich } \\
R^{2}=0.99 \\
1 / n=0.34 \\
K_{F}=27\end{array}$ \\
\hline $\begin{array}{l}\text { Activated carbon } 1240 \\
\quad \text { Ceca [46] }\end{array}$ & 980 & $\begin{array}{l}0.2<C_{\text {adsorbent }}<8 \mathrm{~g} \mathrm{~L}^{-1} \\
C_{0}=2 \mathrm{~g} \mathrm{~L}^{-1} ; T=25^{\circ} \mathrm{C}\end{array}$ & $\begin{array}{l}125^{a} \\
200^{b}\end{array}$ & $\begin{array}{l}\text { Freundlich } \\
R^{2}=0.997 \\
1 / n=0.16 \\
K_{F}=97\end{array}$ \\
\hline $\begin{array}{l}\text { Activated carbon } \\
\text { picactif NC60 [47] }\end{array}$ & 1,062 & $\begin{array}{l}C_{\text {adsorbent }}: \mathrm{NC}^{c} \\
C_{0}: \mathrm{NC}^{c} ; T=20^{\circ} \mathrm{C}\end{array}$ & $\begin{array}{l}170^{a} \\
270^{b}\end{array}$ & $\begin{array}{l}\text { Freundlich } \\
R^{2}=0.99 \\
1 / n=0.14 \\
K_{F}=154\end{array}$ \\
\hline $\begin{array}{l}\text { Activated carbon } \\
\text { picaflo HP [47] }\end{array}$ & 1,454 & $\begin{array}{l}C_{\text {adsorbent }}: \mathrm{NC}^{c} \\
C_{0}: \mathrm{NC}^{c} ; T=20^{\circ} \mathrm{C}\end{array}$ & $\begin{array}{l}80^{a} \\
210^{b}\end{array}$ & $\begin{array}{l}\text { Freundlich } \\
R^{2}=0.99 \\
1 / n=0.31 \\
K_{F}=49\end{array}$ \\
\hline $\begin{array}{l}\text { Faujasite- } \gamma \\
\text { (Zeolite) [10] }\end{array}$ & 608 & $\begin{array}{l}1<C_{\text {adsorbent }}<10 \mathrm{~g} \mathrm{~L}^{-1} \\
C_{0}=240 \mathrm{mg} \mathrm{L}^{-1} ; T=25^{\circ} \mathrm{C}\end{array}$ & $\begin{array}{l}15^{a} \\
115^{b}\end{array}$ & $\begin{array}{l}\text { Generalized Langmuir-Freundlich } \\
R^{2}=0.983 \\
1 / n=2\end{array}$ \\
\hline ZSM-5 (Zeolite) [10] & 308 & $\begin{array}{l}10<C_{\text {adsorbent }}<210 \mathrm{~g} \mathrm{~L}^{-1} \\
C_{0}=240 \mathrm{mg} \mathrm{L}^{-1} ; T=25^{\circ} \mathrm{C}\end{array}$ & $\begin{array}{l}1.3^{a} \\
1.7^{b}\end{array}$ & $\begin{array}{l}\text { Generalized Langmuir-Freundlich } \\
R^{2}=0.991 \\
1 / n=0.23\end{array}$ \\
\hline Mordenite (Zeolite) [10] & 509 & $\begin{array}{l}4<C_{\text {adsorbent }}<13 \mathrm{~g} \mathrm{~L}^{-1} \\
C_{0}=240 \mathrm{mg} \mathrm{L}^{-1} ; T=25^{\circ} \mathrm{C}\end{array}$ & $\begin{array}{l}17^{a} \\
35^{b}\end{array}$ & $\begin{array}{l}\text { Generalized Langmuir-Freundlich } \\
R^{2}=0.980 \\
1 / n=0.38\end{array}$ \\
\hline
\end{tabular}

${ }^{a}$ For $C_{e}=5 \mathrm{mg} \mathrm{L}^{-1}$.

${ }^{b}$ For $C_{e}^{e}=100 \mathrm{mg} \mathrm{L}^{-1}$.

${ }^{\mathrm{N}}$ Not communicated.

to further acidification of the treated water. This more effective degradation can be explained by several phenomena that add up and/or combine.

On the one hand, the decrease of organic specie concentrations can be explained by the retention of the molecules (2,4-DMP and some by-products) by adsorption. Indeed, as shown in Fig. 3a, 2,4-DMP compounds can be removed by adsorption in this reactor with a good efficiency (90\%). However, it is unlikely that all the oxidation by-products of carboxylic acid type are adsorbed. Indeed, previous studies have shown that the by-products of 2,4-DMP ozonation are mainly acetic acid, formic acid and oxalic acid [52] and it is known that these polar molecules are hardly adsorbed on activated carbon [50,54,55]. So even if adsorption plays a role in decreasing TOC, other phenomena also exist.

The second explanation for the stronger decrease in TOC when bpAC is added is an oxidation of the molecules by the radical route. Indeed, it is known that molecular ozone can generate free radicals in contact with solids such as activated carbon [14-16]. As these species are much more reactive than ozone and non-selective, they are able to attack compounds refractory to molecular ozone. Other works reported an increase of the ozone decomposition into hydroxyl radicals in the presence of adsorbent, even at low pH: Valdés and Zaror [17] confirmed in 2006 that aqueous ozone decomposes into free radicals in the presence of AC at $\mathrm{pH}$ 2, Guzman-Perez et al. [25] for atrazine removal at $\mathrm{pH}$ 3 and González-Labrada et al. [18] for ciprofloxacin removal at $\mathrm{pH}$ 3. This higher degradation rate in the presence of free radicals comes from the higher value of the kinetic rate constant: $k_{\mathrm{O} 3-\mathrm{DMP}}=9.910^{4} \mathrm{~L} \mathrm{~mol}^{-1} \mathrm{~s}^{-1}[56]$ and $k_{\mathrm{HO} \cdot \text {-alkyl phenol }}=10^{9}-$ $10^{10} \mathrm{~L} \mathrm{~mol}^{-1} \mathrm{~s}^{-1}[57,58]$.

\subsection{Mechanisms}

A series of catalytic ozonation experiments were carried out with a radical scavenger in order to highlight the existence of a radical pathway. Tert-butyl alcohol $(t-\mathrm{BuOH})$ is commonly used as a radical scavenger as it reacts preferentially with radicals: its reaction rate is much higher with hydroxyl radicals $\left(6 \times 10^{8} \mathrm{~L} \mathrm{~mol}^{-1} \mathrm{~s}^{-1}\right.$ [59]) than with ozone $\left(3 \times 10^{-3} \mathrm{~L} \mathrm{~mol}^{-1} \mathrm{~s}^{-1}[60]\right)$. The adsorption of $t$-BuOH onto $\mathrm{AC}$ is supposed to be negligible and does not compete with 2,4-DMP: it cannot be easily adsorbed by AC because of its high polarity and its very low adsorption rate in comparison with the decomposition rate [23]. Nevertheless, introduced 

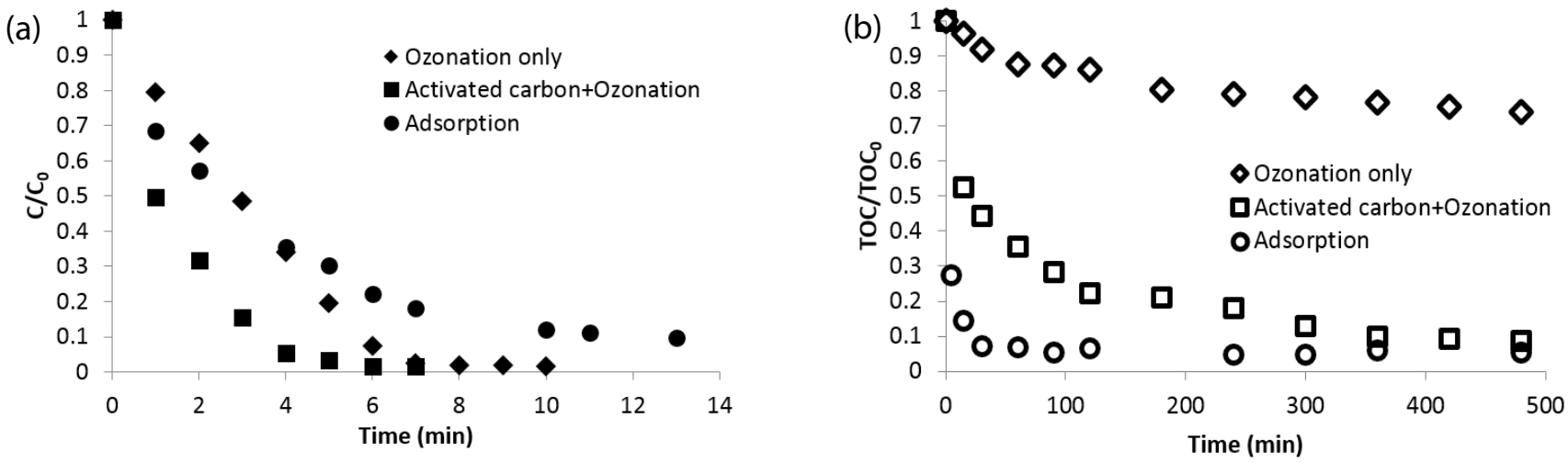

Fig. 3. Dimensionless evolution of the concentration of 2,4-DMP (a) and TOC (b). $[\mathrm{bpAC}]=5 \mathrm{~g} \mathrm{~L}^{-1} ;[2,4-\mathrm{DMP}]_{0}=50 \mathrm{mg} \mathrm{L} \mathrm{L}^{-1}$, $\mathrm{TOC}_{0}=39 \mathrm{mg} \mathrm{L}^{-1}, \mathrm{pH}_{i}=5.3$.

Table 4

Kinetic constants of 2,4-DMP degradation in the synthetic solution and the wastewater spiked with 2,4-DMP

\begin{tabular}{|c|c|c|c|c|c|c|}
\hline & $\begin{array}{l}k_{\text {global }} \\
\left(\min ^{-1}\right)\end{array}$ & $\begin{array}{l}k_{\text {homo }} \\
\left(\min ^{-1}\right)\end{array}$ & $R^{2}$ & $\begin{array}{l}k_{\text {hetero }} \\
\left(\min ^{-1}\right)\end{array}$ & $\delta_{\text {homo }}(\%)=\frac{k_{\text {homo }}}{k_{\text {global }}} \times 100$ & $\delta_{\text {hetero }}(\%)=\frac{k_{\text {hetero }}}{k_{\text {global }}} \times 100$ \\
\hline Synthetic solution & 0.69 & 0.31 & 0.987 & 0.38 & 45 & 55 \\
\hline $\begin{array}{l}\text { Wastewater spiked } \\
\text { with 2,4-DMP }\end{array}$ & 0.62 & 0.38 & 0.986 & 0.24 & 61 & 39 \\
\hline
\end{tabular}

in large excess, there is enough $t$ - $\mathrm{BuOH}$ near the AC surface to react with the radicals formed in the heterogeneous phase.

Fig. 4 shows the evolution of 2,4-DMP concentration during catalytic ozonation with and without $t$-BuOH. In presence of $t-\mathrm{BuOH}$, a complete elimination of 2,4-DMP was obtained after 14 min of catalytic ozonation whereas it only needs 7 min for catalytic ozonation without $t$-BuOH. This shows that a molecular mechanism exists at this acidic $\mathrm{pH}$ since all the 2,4-DMP is eliminated $\left(\mathrm{pH}_{i}=5.3\right)$. Nevertheless, its kinetics is much slower than the radical mechanism one, especially at the beginning of the kinetics: for example, after $3 \mathrm{~min}$, only $63 \%$ of $2,4-\mathrm{DMP}$ is removed, compared with $85 \%$ without $t$ - $\mathrm{BuOH}$ (see the two highlighted points in Fig. 4$)$. The half reaction times $\left(t_{1 / 2}=1 \mathrm{~min}\right.$ without $t-\mathrm{BuOH}$ and $2.5 \mathrm{~min}$ with $t-\mathrm{BuOH})$ evidence this statement and confirm that the presence of the scavenger changes the kinetics of oxidation by reacting with the radicals $\mathrm{HO}^{\bullet}$ instead of 2,4-DMP.

These radical reactions can take place in the bulk liquid phase or on the surface of the activated carbon. In the first case, this can occur if the radicals generated on the surface of the solid have sufficient lifetimes to be able to diffuse in the bulk liquid phase [25]. In the second case, the reactions occur in the adsorbed phase, near the sites of decomposition of ozone. There are major controversies in the literature about the nature of ozone decomposition sites. Some researchers indicate that it is the basic oxygenated functional groups and the delocalized $\pi$ electrons that are responsible for the decomposition of ozone into free radicals [23,61]. Other researchers show that acidic sites can also decompose ozone [17,62]. Our study reinforces this second point of view. Indeed, although our activated carbon bpAC has a large quantity of acidic groups (2.75 meq $\mathrm{g}^{-1}$, Table 2$)$ and no basic group, it seems to decompose ozone into free radicals since radical oxidation takes place. It is very likely that the acidic groups of the surface of the material are at the origin of this decomposition. Indeed, the $\mathrm{pH}_{\mathrm{PZC}}$ of our activated carbon (2.4) being lower than the $\mathrm{pH}$ of water (5.3), the acidic functional groups are present in dissociated form and this deprotonated form can react with ozone. Several researchers have shown that the interaction between ozone and surface acids in deprotonated form can interact with ozone to lead to the formation of highly reactive free radicals such as $\mathrm{O}_{2}^{-\bullet}$ and $\mathrm{O}_{3}^{-\bullet}$, which are promoters of the chain reaction on the carbon surface $[17,63]$.

It is, therefore, likely that four mechanisms are responsible for the good performance of the ozonation mineralization

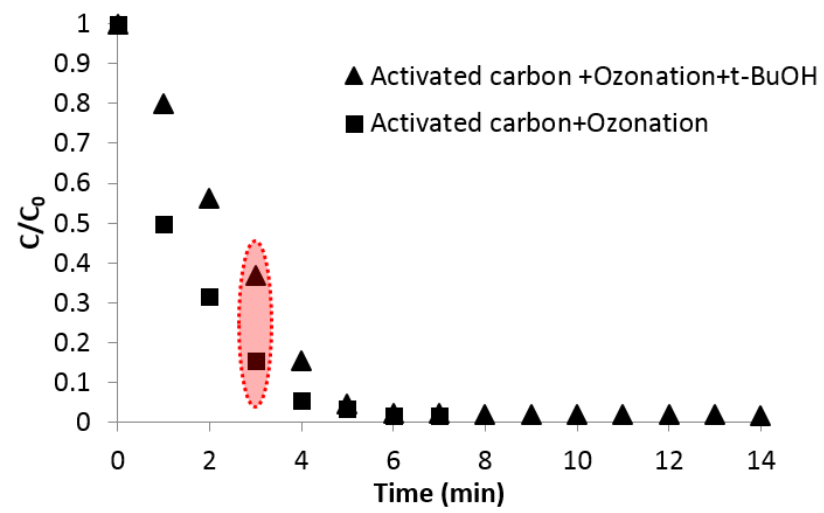

Fig. 4. Dimensionless evolution of the concentration of 2,4-DMP in presence (introduced in excess, $5 \mathrm{~g} \mathrm{~L}^{-1}$ ) and absence of $t$-BuOH. 

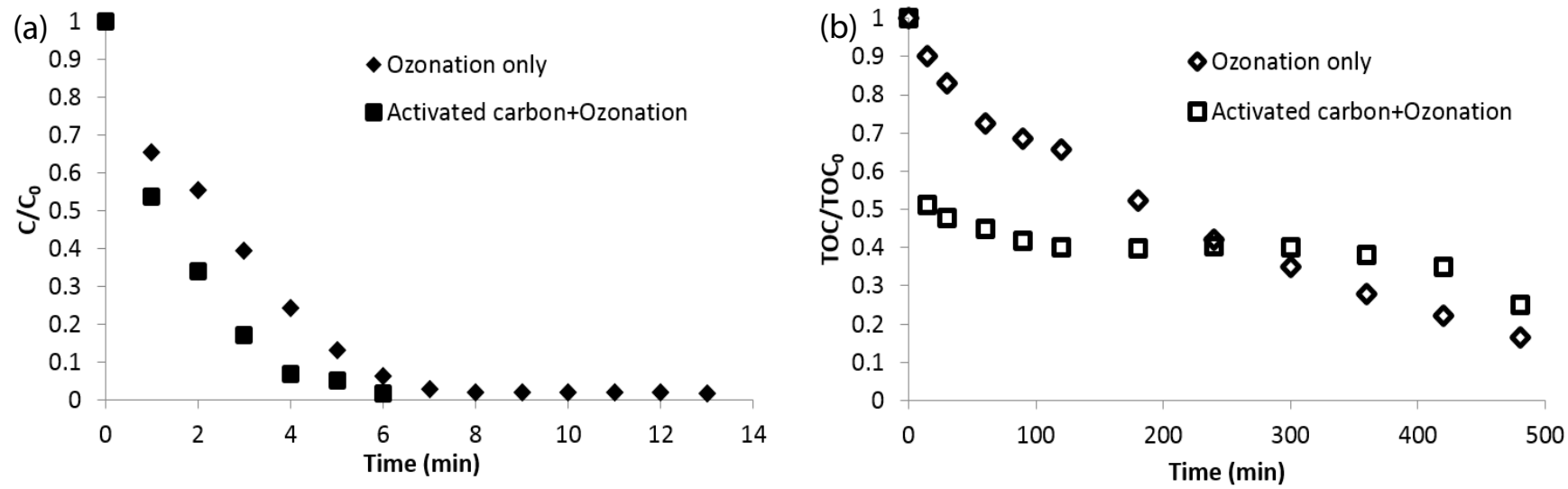

Fig. 5. Dimensionless evolution of 2,4-DMP concentration (a) and TOC (b) spiked wastewater: $[2,4-\mathrm{DMP}]_{0}=50 \mathrm{mg} \mathrm{L}^{-1}, \mathrm{TOC}_{0}=42 \mathrm{mg} \mathrm{L}^{-1}$, $\mathrm{pH}_{i}=8$.

operation in the presence of bpAC: two mechanisms in liquid homogeneous phase, molecular oxidation and radical oxidation, and two mechanisms in heterogeneous phase, radical oxidation in adsorbed phase and adsorption. Considering the results given in Table 4, based on the kinetic constants, the contributions of both heterogeneous and homogeneous mechanisms are of the same order of magnitude, with a slight predominance of the heterogeneous pathway: $55 \%$ for $\delta_{\text {hetero }}$ against $45 \%$ for $\delta_{\text {homo }}$.

\subsection{Application of the catalytic ozonation process to the wastewater spiked with 2,4-DMP}

This study was carried out with the wastewater spiked with 2,4-DMP to evaluate the efficiency of this coupling process in a complex medium. The operating conditions were the same as those applied for the study of the synthetic water. The removal of pollution is followed during $8 \mathrm{~h}$ and results are presented according to 2,4-DMP removal (Fig. 5a) and TOC removal (Fig. 5b).

For these experiments, the initial TOC value includes 2,4-DMP and a low contribution of the wastewater (around $10 \%)$. The same conclusion as for the synthetic solution can be found for 2,4-DMP oxidation (Fig. 5a): the kinetics of 2,4-DMP removals was improved by the presence of bpAC, with a 2,4-DMP complete elimination time divided by 2 . The presence of $\mathrm{HCO}_{3}^{-}$ions does not have much influence on 2,4-DMP degradation kinetics while these ions are known to be radical scavengers. As reported by Sanchez-Polo et al. [64], acidic functions on the AC surface may react with $\mathrm{HCO}_{3}^{-}$to form $\mathrm{H}_{2} \mathrm{CO}_{3}$ and then limit their inhibitor effect. Surprisingly, concerning the TOC evolution (Fig. 5b), single ozonation process applied to the wastewater spiked with 2,4-DMP showed a real decrease of the TOC and a very high elimination of the TOC after $8 \mathrm{~h}$. This better result can be attributed to different $\mathrm{pH}$ conditions. Indeed, the initial $\mathrm{pH}$ of this real wastewater was 8 , with a slight decrease to 6.7 during single ozonation. As it is well known, basic conditions are favourable to the ozone decomposition into hydroxyl radicals. Thus, a better intermediates removal can only be obtained in these experimental conditions rather than with a synthetic solution (acidic conditions).
As it is the case in the synthetic solution, the addition of bpAC improves the efficiency of the TOC removal, but only during $3 \mathrm{~h}$. After this time, the single ozonation process is more efficient than the catalytic one. The presence of natural organic matter (NOM) in wastewater can explain this phenomenon with alternative by-products formation. The presence of NOM can also create unfavourable conditions for the catalyst, being settled on its surface by the NOM. Nevertheless, the residence time in continuous processes being less than $3 \mathrm{~h}$, the interest of the addition of bpAC is clearly shown: it enhanced the kinetics in a dramatic way.

In order to distinguish the homogeneous and heterogeneous reactions share, the modelling of the kinetics of 2,4-DMP removal during the first $5 \mathrm{~min}$ was done and the values $k_{\text {homo }}=0.38 \mathrm{~min}^{-1}$ and $k_{\text {global }}=0.62 \mathrm{~min}^{-1}$ were determined (Table 4). Here, the homogeneous reactions are predominant. Unlike the synthetic solution, the contribution of heterogeneous mechanism $\left(\delta_{\text {hetero }}=39 \%\right)$ is less important in this case. This may be due to the presence of NOM in effluent sampled from domestic sewage treatment. The TOC removal is then mainly due to the direct and indirect action of ozone.

\section{Conclusion}

This work shows that, for the first time, it is possible to develop a valuable activated carbon from Borassus palm waste (bpAC). This bpAC presents a high specific surface, with a good adsorption capacity of 2,4-DMP, a model phenolic compound. Furthermore, the presence of bpAC in the ozonation process showed a quantitative and quick removal of 2,4-DMP and the TOC in the synthetic solution and the wastewater spiked with 2,4-DMP. The study conducted with $t-\mathrm{BuOH}$, a radical scavenger, showed that hydroxyl radicals were strongly responsible to the 2,4-DMP degradation during catalytic ozonation with bpAC. The presence of both molecular ozone and radicals, in solution and also at the surface of bpAC, may be responsible for the fast kinetics obtained. A global model of the first order based on adding the contributions of the different mechanisms of the catalytic ozonation made it possible on the one hand, to correctly represent the kinetics of degradation of 2,4-DMP, and on the other hand to estimate the kinetics contribution 
of heterogeneous reactions and homogeneous reactions to eliminate this pollutant. The contribution of heterogeneous mechanisms being more important in the case of the synthetic solution $\left(\delta_{\text {hetero }}=55 \%\right)$ showed that the reactions occurred mainly on the surface of bpAC. However, in the case of the wastewater spiked with $2,4-\mathrm{DMP}, \delta_{\text {homo }}$ was more important $(61 \%)$ because of the initial $\mathrm{pH}(8.0)$, which confirms the hypothesis that ozone decomposition is favourable in basic conditions.

\section{Acknowledgement}

This work was supported by the project Appui à la Modernisation et à la Réforme des Universités et Grandes Ecoles de Côte D'Ivoire (AMRUGE-CI).

\section{References}

[1] Activated Carbon Market Size, Share \& Trends Analysis Report By Product (Powdered Activated Carbon, Granular Activated Carbon), By Application, By End-use, And Segment Forecasts, Grand View Research, 2018.

[2] S. Wong, N. Ngadi, I.M. Inuwa, O. Hassan, Recent advances in applications of activated carbon from biowaste for wastewater treatment: a short review, J. Cleaner Prod., 175 (2018) 361-375.

[3] E. Menya, P.W. Olupot, H. Storz, M. Lubwama, Y. Kiros, Production and performance of activated carbon from rice husks for removal of natural organic matter from water: a review, Chem. Eng. Res. Des., 129 (2018) 271-296.

[4] J. Matos, J. Laine, J.M. Hermann, D. Uzcategui, J.L. Brito, Influence of activated carbon upon titania on aqueous photocatalytic consecutive runs of phenol photodegradation, Appl. Catal., B, 70 (2007) 461-469.

[5] P. González-García, Activated carbon from lignocellulosics precursors: a review of the synthesis methods, characterization techniques and applications, Renewable Sustainable Energy Rev., 82 (2018) 1393-1414.

[6] R.W. Coughlin, Carbon as Adsorbent and Catalyst, Ind. Eng. Chem. Prod. Res. Dev., 8 (1969) 12-23.

[7] A. Fortuny, J. Font, A. Fabregat, Wet air oxidation of phenol using active carbon as catalyst, Appl. Catal., B, 19 (1998) 165-173.

[8] C. Andriantsiferana, E.F. Mohamed, H. Delmas, Photocatalytic degradation of an azo-dye on $\mathrm{TiO}_{2} /$ activated carbon composite material, Environ. Technol., 35 (2014) 355-363.

[9] S. Khamparia, D.K. Jaspal, Adsorption in combination with ozonation for the treatment of textile waste water: a critical review, Front. Environ. Sci. Eng., 11 (2017) 8.

[10] W. Aboussaoud, M.-H. Manero, J.-S. Pic, H. Debellefontaine, Combined ozonation using alumino-silica materials for the removal of 2,4-dimethylphenol from water, Ozone Sci. Eng., 36 (2014) 221-228.

[11] A. Ikhlaq, B. Kasprzyk-Hordern, Catalytic ozonation of chlorinated VOCs on ZSM-5 zeolites and alumina: formation of chlorides, Appl. Catal., B, 200 (2017) 274-282.

[12] W. Chen, X. Li, Z. Pan, S. Ma, L. Li, Effective mineralization of diclofenac by catalytic ozonation using Fe-MCM-41 catalyst, Chem. Eng. J., 304 (2016) 594-601.

[13] J. Wang, Z. Bai, Fe-based catalysts for heterogeneous catalytic ozonation of emerging contaminants in water and wastewater, Chem. Eng. J., 312 (2017) 79-98.

[14] T. Merle, J.-S. Pic, M.-H. Manero, H. Debellefontaine, Comparison of activated carbon and hydrophobic zeolite efficiencies in 2,4-dichlorophenol advanced ozonation, Ozone Sci. Eng., 32 (2010) 391-398.

[15] D. Gümüs, F. Akbal, A comparative study of ozonation, iron coated zeolite catalyzed ozonation and granular activated carbon catalyzed ozonation of humic acid, Chemosphere, 174 (2017) 218-231.

[16] O. Rozas, C. Baeza, K. Núñez, A. Rossner, R. Urrutia, H.D Mansilla, Organic micropollutants (OMPs) oxidation by ozone: effect of activated carbon on toxicity abatement, Sci. Total Environ., 590-591 (2017) 430-439.

[17] H. Valdés, C.A. Zaror, Heterogeneous and homogeneous catalytic ozonation of benzothiazole promoted by activated carbon: kinetic approach, Chemosphere, 65 (2006) 1131-1136.

[18] K. González-Labrada, R. Richard, C. Andriantsiferana, H. Valdés, J.-H. Ulises-Javier, M.-H. Manero, Enhancement of ciprofloxacin degradation in aqueous system by heterogeneous catalytic ozonation, Environ. Sci. Pollut. Res., (2018). doi:10.1007/s11356018-3559-9

[19] F.J. Beltrán, J. Rivas, P. Álvarez, R. Montero-de-Espinosa, Kinetics of heterogeneous catalytic ozone decomposition in water on an activated carbon, Ozone Sci. Eng., 24 (2002) 227-237.

[20] B. Kasprzyk-Hordern, P. Andrzejewski, J. Nawrocki, Catalytic ozonation of gasoline compounds in model and natural water in the presence of perfluorinated alumina bonded phases, Ozone Sci. Eng., 27 (2005) 301-310.

[21] A. Flouret, M.C. de Almeida, T.F. de Oliveira, F.P. de Sa, Advanced treatment of phenol by $\mathrm{H}_{2} \mathrm{O}_{2} / \mathrm{UV} /$ activated carbon coupling: influence of homogeneous and heterogeneous phase, Can. J. Chem. Eng., 96 (2018) 1979-1985.

[22] M. Sánchez-Polo, U. von Gunten, J. Rivera-Utrilla, Efficiency of activated carbon to transform ozone into ${ }^{\circ} \mathrm{OH}$ radicals: Influence of operational parameters, Water Res., 39 (2005) 3189-3198.

[23] P.M. Alvárez, J.F. García-Araya, F.J. Beltrán, I. Giráldez, J. Jaramillo, V. Gómez-Serrano, The influence of various factors on aqueous ozone decomposition by granular activated carbons and the development of a mechanistic approach, Carbon, 44 (2006) 3102-3112.

[24] T.F. de Oliveira, O. Chedeville, H. Fauduet, B. Cagnon, Use of ozone/activated carbon coupling to remove diethyl phthalate from water: influence of activated carbon textural and chemical properties, Desalination, 276 (2011) 359-365.

[25] C.A. Guzman-Perez, J. Soltan, J. Robertson, Kinetics of catalytic ozonation of atrazine in the presence of activated carbon, Sep. Purif. Technol., 79 (2011) 8-14.

[26] M. Danish, T. Ahmad, A review on utilization of wood biomass as a sustainable precursor for activated carbon production and application, Renewable Sustainable Energy Rev., 87 (2018) 1-21.

[27] A. Hussain, S.K. Dubey, V. Kumar, Kinetic study for aerobic treatment of phenolic wastewater, Water Resour. Ind., 11 (2015) 81-90.

[28] G. Garcia, J.L.B. Venceslada, P.R. Jimenez Pena, E.R. Gomez, Biodegradation of phenol compounds in vinasse using Aspergillus terreus and Geotrichum candidum, Water Res., 31 (1997) 2005-2011.

[29] S. Brunauer, P.H. Emmett, E. Teller, Adsorption of gases in multimolecular layers, J. Am. Chem. Soc., 60 (1938) 309-319.

[30] G. Horváth, K. Kawazoe, Method for the calculation of effective pore size distribution in molecular sieve carbon, J. Chem. Eng. Jpn, 16 (1983) 470-475.

[31] E.P. Barrett, L.G. Joyner, P.P. Halenda, The determination of pore volume and area distributions in porous substances. I. Computations from nitrogen isotherms, J. Am. Chem. Soc., 73 (1951) 373-380.

[32] H.P. Boehm, Some aspects of the surface chemistry of carbon blacks and other carbons, Carbon, 32 (1994) 759-769.

[33] M.V. Lopez-Ramon, F. Stoeckli, C. Moreno-Castilla, F. CarrascoMarina, On the characterization of acidic and basic surface sites on carbons by various techniques, Carbon, 37 (1999) 1215-1221.

[34] J.L. Acero, K. Stemmler, U. Von Gunten, Degradation kinetics of atrazine and its degradation products with ozone and $\mathrm{OH}$ radicals: a predictive tool for drinking water treatment, Environ. Sci. Technol., 34 (2000) 591-597.

[35] T.F. de Oliveira, O. Chedeville, B. Cagnon, H. Fauduet, Degradation kinetics of DEP in water by ozone/activated carbon process: influence of $\mathrm{pH}$, Desalination, 269 (2011) 271-275.

[36] C. Andriantsiferana, C. Julcour-Lebigue, C. Creanga-Manole, H. Delmas, Competitive adsorption of $p$-hydroxybenzoic acid and phenol on activated carbon: experimental study and modeling, J. Environ. Eng., 139 (2013) 402-409.

[37] I. Quesada-Peñate, C. Julcour-Lebigue, U.-J. Jáuregui-Haza, A.-M. Wilhelm, H. Delmas, Comparative adsorption of 
levodopa from aqueous solution on different activated carbons, Chem. Eng. J., 152 (2009) 183-188.

[38] E.F. Mohamed, C. Andriantsiferana, A.-M. Wilhelm, H. Delmas, Competitive adsorption of phenolic compounds from aqueous solution using sludge-based activated carbon, Environ. Technol., 32 (2011) 1325-1336.

[39] M.A. Yahya, Z. Al-Qodah, C.W. Zanariah Ngah, Agricultural bio-waste materials as potential sustainable precursors used for activated carbon production: a review, Renewable Sustainable Energy Rev., 46 (2015) 218-235.

[40] O. Ioannidou, A. Zabaniotou, Agricultural residues as precursors for activated carbon production-A review, Renewable Sustainable Energy Rev., 11 (2007) 1966-2005.

[41] N.V. Sych, S.I. Trofymenko, O.I. Poddubnaya, M.M. Tsyba, V.I. Sapsay, D.O. Klymchuk, A.M. Puziy, Porous structure and surface chemistry of phosphoric acid activated carbon from corncob, Appl. Surf. Sci., 261 (2012) 75-82.

[42] M. Danish, R. Hashim, M.N.M. Ibrahim, O. Sulaiman, Effect of acidic activating agents on surface area and surface functional groups of activated carbons produced from Acacia mangium wood, J. Anal. Appl. Pyrolysis, 104 (2013) 418-425.

[43] A. Ould-Idriss, M. Stitou, E.M. Cuerda-Correa, C. FernándezGonzález, A. Macías-García, M.F. Alexandre-Franco, V. GómezSerrano, Preparation of activated carbons from olive-tree wood revisited. I. Chemical activation with $\mathrm{H}_{3} \mathrm{PO}_{4^{\prime}}$ Fuel Process. Technol., 92 (2011) 261-265.

[44] M. Ahmedna, W.E. Marshall, A.A. Husseiny, R.M. Rao, I. Goktepe, The use of nutshell carbons in drinking water filters for removal of trace metals, Water Res., 38 (2004) 1062-1068.

[45] W. Ao, J. Fu, X. Mao, Q. Kang, C. Ran, Y. Liu, H. Zhang, Z. Gao, J. Li, G. Liu, J. Dai, Microwave assisted preparation of activated carbon from biomass: a review, Renewable Sustainable Energy Rev., 92 (2018) 958-979.

[46] S. Bourneuf, M. Jacob, C. Albasi, S. Sochard, R. Richard, M.-H. Manero, Desorption experiments and modeling of micropollutants on activated carbon in water phase: application to transient concentrations mitigation, Int. J. Environ. Sci. Technol., 13 (2016) 1-10.

[47] N. Lesage, Etude d'un procédé hybride Adsorption/Bioréacteur à membranes pour le traitement des effluents industriels, Thèse de l'Université de Toulouse, INSA, 2005.

[48] C. Moreno-Castilla, Adsorption of organic molecules from aqueous solutions on carbon materials, Carbon, 42 (2004) 83-94.

[49] R. Kamaraj, P. Ganesan, S. Vasudevan, Removal of lead from aqueous solutions by electrocoagulation: isotherm, kinetics and thermodynamic studies, Int. J. Environ. Sci. Technol., 12 (2015) 683-692.

[50] J. Vittenet, J. Rodriguez, E. Petit, D. Cot, J. Mendret, A. Galarneau, S. Brosillon, Removal of 2,4-dimethylphenol pollutant in water by ozonation catalyzed by SOD, LTA, FAU-X zeolites particles obtained by pseudomorphic transformation (binderless), Microporous Mesoporous Mater., 189 (2014) 200-209.
[51] M. Trapido, Y. Veressinina, R. Munter, Advanced oxidation processes for degradation of 2,4-dichlo- and 2,4-dimethylphenol, J. Environ. Eng., 124 (1998) 690-694.

[52] J. Vittenet, W. Aboussaoud, J. Mendret, J.-S. Pic, H. Debellefontaine, N. Lesage, K. Faucher, M.-H. Manero, F. ThibaultStarzyk, H. Leclerc, A. Galarneau, S. Brosillon, Catalytic ozonation with $\gamma-\mathrm{Al}_{2} \mathrm{O}_{3}$ to enhance the degradation of refractory organics in water, Appl. Catal., A, 504 (2015) 519-532.

[53] H. Valdés, M. Sánchez-Polo, J. Rivera-Utrilla, C.A. Zaror, Effect of ozone treatment on surface properties of activated carbon, Langmuir, 18 (2002) 2111-2116.

[54] A. Yousuf, F. Bonk, J.-R. Bastidas-Oyanedel, J.E. Schmidt, Recovery of carboxylic acids produced during dark fermentation of food waste by adsorption on Amberlite IRA-67 and activated carbon, Bioresour. Technol., 217 (2016) 137-140.

[55] C.S. López-Garzón, A.J.J. Straathof, Recovery of carboxylic acids produced by fermentation, Biotechnol. Adv., 32 (2014) 873-904.

[56] M.D. Gurol, S. Nejouinaini, Kinetic behavior of ozone in aqueous solutions of substituted phenols, Ind. Eng. Chem. Fundam., 23 (1984) 54-60.

[57] A.B Ross, A. Farhataziz, Selective specific rates of reactions of transients in water and aqueous solutions. Part III. Hydroxyl radical and perhydroxyl radical and their radical ions, Natl. Stand. Ref. Data Ser., USA Natl. Bur. Stand., 59 (1977) 1-22.

[58] S. Mandal, Reaction rate constants of hydroxyl radicals with micropollutants and their significance in advanced oxidation processes, J. Adv. Oxid. Technol., 21 (2018) 178-195

[59] G.V. Buxton, C.L. Greenstock, W.P. Helman, A.B. Ross, Critical review of rate constants for reactions of hydrated electrons, hydrogen atoms and hydroxyl radicals $\left({ }^{\circ} \mathrm{OH} /{ }^{\circ} \mathrm{O}-\right.$ in aqueous solution, J. Phys. Chem. Ref. Data, 17 (1988) 513-531.

[60] J. Hoigné, H. Bader, Rate constants of reactions of ozone with organic and inorganic compounds in water-I: Non-dissociating organic compounds, Water Res., 17 (1983) 173-183.

[61] L. Xing, Y. Xie, H. Cao, D. Minakata, Y. Zhang, J.C. Crittenden, Activated carbon-enhanced ozonation of oxalate attributed to HO• oxidation in bulk solution and surface oxidation: effects of the type and number of basic sites, Chem. Eng. J., 245 (2014) 71-79.

[62] H. Dehouli, O. Chedeville, B. Cagnon, V. Caqueret, C. Porte, Influences of $\mathrm{pH}$, temperature and activated carbon properties on the interaction ozone/activated carbon for a wastewater treatment process, Desalination, 254 (2010) 12-16.

[63] J. Nawrocki, Catalytic ozonation in water: controversies and questions. discussion paper, Appl. Catal., B, 142-143 (2013) $465-471$.

[64] M. Sanchez-Polo, E. Salhi, J. Rivera-Utrilla, U. Von Gunten, Combination of ozone with activated carbon as an alternative to conventional advanced oxidation processes, Ozone Sci. Eng., 28 (2006) 237-245. 